\title{
BMJ Open Mortality inequalities by occupational status and type of job in men and women: results from the Rome Longitudinal Study
}

\author{
Lorenzo Paglione (D) , ${ }^{1,2}$ Laura Angelici (D) ,2 Marina Davoli (D) , ${ }^{2}$ Nera Agabiti (D) , ${ }^{2}$ \\ Giulia Cesaroni (1) ${ }^{2}$
}

To cite: Paglione $L$, Angelici L, Davoli M, et al. Mortality inequalities by occupational status and type of job in men and women: results from the Rome Longitudinal Study. BMJ Open 2020;10:e033776. doi:10.1136/ bmjopen-2019-033776

- Prepublication history for this paper is available online. To view these files, please visit the journal online (http://dx.doi. org/10.1136/bmjopen-2019033776).

Received 22 August 2019 Revised 12 April 2020 Accepted 14 April 2020

\section{Check for updates}

\section{(c) Author(s) (or their} employer(s)) 2020. Re-use permitted under CC BY-NC. No commercial re-use. See rights and permissions. Published by BMJ.

${ }^{1}$ Department of Civil,

Constructional and

Environmental Engineering,

Sapienza University of Rome,

Roma, Italy

${ }^{2}$ Department of Epidemiology, Lazio Regional Health Service, ASL Roma 1, Roma, Italy

Correspondence to Dr Lorenzo Paglione; I.paglione@deplazio.it

\section{ABSTRACT}

Objectives Socioeconomic inequalities have a strong impact on population health all over the world. Occupational status is a powerful determinant of health in rich societies. We aimed at investigating the association between occupation and mortality in a large metropolitan study. Design Cohort study.

Setting Rome, capital of Italy.

Participants We used the Rome Longitudinal Study, the administrative cohort of residents in Rome at the 2001 general census, followed until 2015. We selected residents aged 15-65 years at baseline. For each subject, we had information on sex, age and occupation (occupational status and type of job) according to the Italian General Census recognition.

Main outcome measures We investigated all-cause, cancer, cardiovascular and accidental mortality, major causes of death in the working-age population. We used Cox proportional hazards models to investigate the association between occupation and all-cause and causespecific mortality in men and women.

Results We selected 1466726 subjects (52.1\% women). 42715 men and 29915 women died during the follow-up. In men, $47.8 \%$ of deaths were due to cancer, $26.7 \%$ to cardiovascular causes and $6.4 \%$ to accidents, whereas in women $57.8 \%$ of deaths were due to cancer, $19.3 \%$ to cardiovascular causes and $3.5 \%$ to accidents. We found an association between occupational variables and mortality, more evident in men than in women. Compared with employed, unemployed had a higher risk of mortality for all causes with an $\mathrm{HR}=1.99(95 \% \mathrm{Cl} 1.92$ to 2.06$)$ in men and an $\mathrm{HR}=1.49(95 \% \mathrm{Cl} 1.39$ to 1.60$)$ in women. Compared with high-qualified non-manual workers, non-specialised manual workers had a higher mortality risk ( $\mathrm{HR}=1.68$, $95 \% \mathrm{Cl} 1.59$ to 1.77 and $\mathrm{HR}=1.30,95 \% \mathrm{Cl} 1.20$ to 1.40 , for men and women, respectively).

Conclusions This study shows the importance of occupational variables as social health determinants and provides evidence for policy-makers on the necessity of integrated and preventive policies aimed at improving the safety of the living and the working environment.

\section{INTRODUCTION}

The 10th of the United Nations Sustainable Development Goals is to 'reduce inequality
Strengths and limitations of this study

- The study was based on 1.5 million working-age residents in a metropolitan area, followed for 14 years.

- Census information, linked to health data, allowed a detailed analysis of health outcomes related to occupational status and type of job at individual level.

- Occupational status and type of job permitted to highlight sex inequalities related to job prestige and job market accessibility, both strongly dependent from the context.

- The lack of information about career histories was the principal limit of our study.

within and among countries'. ${ }^{1}$ Socioeconomic inequalities in health were identified and systematised during the $1990 \mathrm{~s},{ }^{2}$ and analysed by WHO 'Commission on Social Determinants of Health'. ${ }^{3}$ They are defined as systematic, avoidable and uneven. They emerge whenever they are measured, also in a rich or advanced country, ${ }^{4}$ and they are inequitable. ${ }^{5}$ Within the social scale, those who occupy a higher position have better health outcomes than those below. In Europe, mortality is decreasing faster in higher than in lower socioeconomic groups, with a subsequent increase of socioeconomic inequalities. ${ }^{67}$ Inequalities can be highlighted using different indicators of socioeconomic position, that is, educational level, income, occupational status and occupational class. In order to identify areas of intervention for public health integrated policies, a strong baseline of evidence is required.

In Italy, most studies on socioeconomic differentials in health used educational level as an indicator of socioeconomic position. ${ }^{89}$ The 'Italian Atlas of Mortality Inequalities by Educational Level' reported a wide range of inequalities. $^{8}$ There are differences in life 
expectancy by educational level in the whole country with inequalities more evident in men than in women. In the majority of Italian regions, the population attributable fraction, that is, the proportion of deaths that could have been avoided if the population with a low-medium education had the same mortality rate as the population with a high educational level, ranged between $15 \%$ and $25 \%$ in men and between $5 \%$ and $15 \%$ in women. ${ }^{8}$ Other Italian studies focused on metropolitan areas, in particular Turin and Rome. In Turin, from 1990 to 2010, absolute inequalities in mortality by educational level were decreasing, but relative inequalities were widening, especially in men. ${ }^{10}$ In Rome, a gradient in mortality by educational level was reported. ${ }^{9}$ This gradient, more evident in men than in women, was wider in young and middle age groups compared with the elderly, and was present for all investigated causes of deaths, in particular for cardiovascular diseases (CVD) and accidents. ${ }^{9}$

If educational level refers to gaining a 'biological capital' in the first part of life,${ }^{11}$ occupational status and work-related variables are connected to living standards and material resources. ${ }^{12}$

Occupation can reflect social standing, access to better care, social network and stress control, and can determine exposure to professional hazards. ${ }^{13}{ }^{14}$ Several international studies on occupational inequalities included Italian data from Turin. Since Turin is a northern industrial city, the association between occupational status and mortality could differ from the central and southern part of the country. ${ }^{15}$ Moreover, numerous studies that used occupation as an indicator restricted the analyses to the male population, or to specific outcomes. ${ }^{1416-19}$

Women's health has been much analysed using a role framework, failing to investigate both the effect of socioeconomic position and the hazards related to domestic work. ${ }^{20}$ Women's work in Europe has to be combined with the domestic role, with lower participation in planning and fewer career perspectives. ${ }^{21}{ }^{22}$ In Italy, which is the second European country for gender employment gap, ${ }^{22}$ it is crucial to investigate women's work-related health inequalities including those outside the job market (housewives, unable to work and retired).

In Rome, social inequalities in health have historical roots. ${ }^{23}$ In recent years, several studies have highlighted a clear separation within the city, with a core-periphery gradient in the distribution of social determinants of health. ${ }^{24}{ }^{25}$ The municipality of Rome covers an area of $1285 \mathrm{~km}^{2}$, with a very low population density (2223 residents $/ \mathrm{km}^{2}$ ), a fragmented urban pattern ${ }^{26}$ and a significant urban sprawl, related to difficulties in moving and in access to services. ${ }^{27}$ In comparison, New York covers $1214 \mathrm{~km}^{2}$ with a density of 11000 residents $/ \mathrm{km}^{2}$. Since its designation as capital city (1871), Rome has been characterised by an economy based essentially on the tertiary sector, in particular the public administration and related services. The Rome municipality also includes an agricultural area of about 43000 ha, which means that a share of the economy is based on farming, breeding activities and product processing, employing low qualified and manual workers. Due to the political choice of the late 19th century to ensure the future of Rome as an administrative capital without a strong industrial sector to avoid large masses of manual workers, ${ }^{28}$ there is a myriad of smallscale activities, mainly linked to the construction sector.

Analysing occupational variables can provide a better understanding of how inequalities impact on the 'biological capital' during the second part of life, complementing previous studies on inequalities in mortality by educational level in Rome. ${ }^{9}$ The aim of this study was to evaluate the role of inequalities in all-cause, and causespecific mortality, separately for men and women, related to occupational status and job type in Rome, using a large administrative census cohort.

\section{METHODS}

\section{Design and study population}

We used the Rome longitudinal study, the 2001 census cohort of residents in Rome who were not living in institutions (prisons, hospitals and nursing homes) on 21st October 2001 (census reference day). ${ }^{29}{ }^{30}$ The information collected in the census questionnaire includes sex, age, education, marital status, place of birth, occupational status and type of job. The subjects were followed through record linkage procedures, using an anonymous identifier, with the Municipal Register data and the Regional Health Information System, from the census reference day until they moved from Rome, they died or December 2015, whichever came first. Cause of death was available coded by the International Classification of Disease-Ninth Revision (ICD-9). ${ }^{31}$ From the original census cohort ( $\mathrm{n}=2118670),{ }^{9}$ we included subjects with available health information $(99.9 \%)$ and we selected those aged between 15 and 65 years at the beginning of the follow-up.

\section{Patient and public involvement}

The study is included in the national statistical programme 2017-2019. Due to privacy policy restrictions, we do not have access to individual contact information and it was impossible to involve subjects in any part of the study. Considering the mission of our public Institution, our aim was to disseminate results to the population, addressing also specific public health issues for local health and administrative authorities in order to tackle health inequalities.

\section{Exposure variables}

Among the census variables, we selected two categorical variables related to occupation: occupational status (employed, looking for the first job, unemployed, starting a new job, student, homemaker, retired, national service, unable to work, other condition), and type of job. The type of job included as categories: army forces, manager (intended as high-level managerial role in public or private sectors), high-qualified non-manual worker, 
medium-qualified non-manual worker, low-qualified nonmanual worker, sale or service, farmer, high-qualified manual worker, medium-qualified manual worker and non-specialised manual worker. We maintained the census categorisations of the variables, as collected in the survey of the 14th and the previous general censuses. In addition, we selected sex, date of birth and place of birth (Rome, Central Italy, Northern Italy, Southern Italy and abroad).

\section{Outcomes}

We analysed all-cause mortality, and we selected cancer mortality (ICD-9 codes 140-239), mortality from CVD (ICD-9 codes 390-459) and accidental mortality (ICD-9 codes 800-999). In addition, we analysed accidental causes because they might be related to the working activity.

\section{Statistical analysis}

We used Kaplan-Meier estimator to estimate the survival function according to occupational status and type of job for men and women. We produced Kaplan-Meier curves and performed a log-rank test to evaluate differences in survival function.

We investigated the proportionality assumption plotting Kaplan-Meier curves and Schoenfeld residuals for the work-related variables. Since occupational status did not satisfy the proportionality assumption, we collapsed 'starting a new job' and 'employed', we collapsed 'retired', 'unable to work' and 'other conditions', and for men, we categorising 'homemakers' as 'unemployed', and those 'in national service' as 'students'.

We used Cox proportional hazard models to investigate the association between the two occupational variables (occupational status and type of job) and mortality (all cause and cause specific) in men and women. We calculated HRs with $95 \%$ CIs. We used time of follow-up as time axis, and we stratified the baseline hazard function by single-year age groups to account for changes in risks by age. Although we decided to calculate HRs separately for men and women, we tested for interaction between the occupational variables and sex using log-likelihood ratio test.

We carried out all the analyses using STATA V.12.

\section{RESULTS}

We selected 1466726 residents, aged $15-65$ years $(47.9 \%$ men, $52.1 \%$ women), followed for 18695055 person years.

Table 1 shows the characteristics of the study population, the average years of follow-up, the number of deaths and the percentage of deaths from cancer, CVD and accidental causes. The mean baseline age was 41 years (SD 14) for men and 42 years (SD 14) for women. Regarding marital status, we found more single men $(40.0 \%)$ then women $(33.3 \%)$, and more divorced or separated and widowed women ( $8.1 \%$ and $4.1 \%$, respectively) than men
( $4.9 \%$ and $0.8 \%$, respectively). The distribution of level of education was similar between sexes. Data on the area of birth confirm that Rome is attractive for both, foreigners and workers from the rest of Italy, in particular from the regions of southern Italy ( $16.1 \%$ men and $16.7 \%$ women). Regarding the occupational status, a gap in employment between men $(65.2 \%)$ and women $(45.8 \%)$, and a high prevalence of homemakers among women $(n=198433$, $26.0 \%$ ) emerged.

During the study period, we observed 42715 deaths in men and 29915 in women, mostly due to cancer and CVD, which accounted for $70 \%-80 \%$ of the total mortality for those aged 40 or older. In the 15-29 age class, men mostly died for accidental causes (47.5\% of all deaths), while for women the first cause of death was cancer (33.9\%), followed by accidents $(25.9 \%)$. In the $60-65$ age class, the most prevalent cause was cancer for both, men (50.4\%) and women $(51.1 \%)$.

Table 2 provides information on the type of job in the 808167 employed subjects. Managerial roles were mainly held by men $(13.3 \% \mathrm{n}=61099$ of men vs $6.5 \% \mathrm{n}=22735$ of women), $20 \%$ of men and $26 \%$ of women were mediumqualified non-manual workers. $11.5 \%$ of men and only $2.6 \%$ of women were high-qualified manual workers, while $9.2 \%$ of men and $11.1 \%$ of women were employed in nonspecialised manual occupations. While male occupation was equally distributed between manual and non-manual jobs, women were mostly employed in non-manual positions, and among manual occupations especially in the lower position (non-specialised manual workers).

Figure 1 shows the Kaplan-Meier curves according to occupational status and type of job for men (A, C) and women (B, D). Kaplan-Meier curves showed significant differences in event-free survival rates among occupational status and type of job $(\log$-rank $\mathrm{p}<0.001)$ both, in men and women.

Table 3 shows the age-adjusted association between occupational status and mortality in men and women. Compared with those employed, we found a higher mortality risk both, in men and women, among 'looking for the first job', unemployed and 'retired or in other conditions' categories. The association between unemployment and all-cause mortality was stronger in men than in women. Unemployed men had an HR for all-cause mortality of 1.99 (95\% CI 1.92 to 2.06) compared with the employed. The strength of association was quite similar when we considered cause-specific mortality, except for accidental mortality, with an HR of 2.31 (95\% CI 2.05 to $2.60)$. In women, we observed an attenuated pattern, with an HR of the unemployed compared with the employed of 1.49 (95\% CI 1.39 to 1.60) in all-cause mortality. Nevertheless, we found an increased mortality risk in female homemakers, who had an HR=1.25 (95\% CI 1.21 to 1.29) for all cause and an HR=1.29 (95\% CI 1.09 to 1.53) for accidental mortality compared with employed women.

Table 4 shows the age-adjusted HRs by type of job, for employed men and women. In both sexes, compared with high-qualified non-manual workers, all other categories 


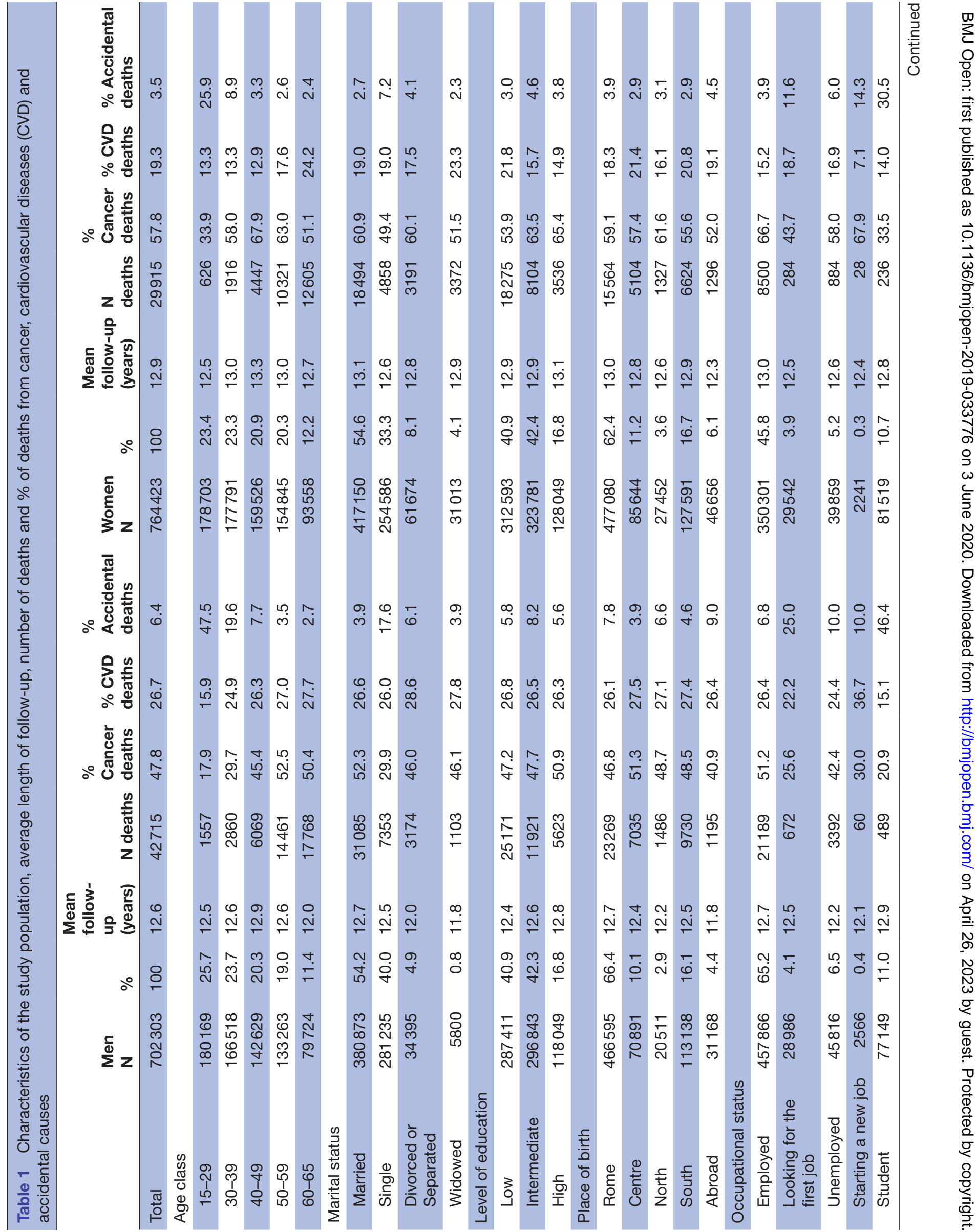






showed a greater risk, with some differences between men and women (log likelihood ratio test for interaction between type of job and sex showed a $p<0.001$ for all-cause and cancer mortality). In men, we found consistent and similar associations in all-cause, cancer and CVD mortality. On the contrary, we found a particularly strong association with accidental mortality, with an HR for nonspecialised male manual workers of 2.06 (95\% CI 1.67 to 2.53). In women, the strength of the association between type of job and mortality depended on the specific cause of mortality. For all-cause mortality, the pattern of association was similar to men in non-manual workers, and was weaker than in men for manual workers. The association between type of job and cancer mortality in women was weaker than in men. In contrast, we found a similar association between type of job and CVD mortality in men and women. There was no evidence of an association between type of job and accidental mortality, except for women working in sale or service.

\section{DISCUSSION}

Our study, based on a cohort of 1466726 residents in Rome, and followed for 14 years, showed significant differences in mortality by occupational status and type of job both, in men and in women. Globally, we found stronger occupational inequalities in men than in women for all outcomes, except for CVD mortality. The bigger difference in mortality risk by type of job in men respect to women is coherent with reports in other settings. ${ }^{6}{ }^{32}$ However, it is difficult to perform international comparison, because occupational status (ie, employed vs unemployed), and type of job (ie, skilled vs non-skilled workers), depend on the contextual productive tissue, on local legislation, and on the variables categorisation.

We found a disadvantage for all categories of occupation status in both sexes compared with the employed, except for students. This pattern, for men, was confirmed in the international literature, ${ }^{6}$ in particular in the context of other European countries, with a $64 \%$ increased risk in the unemployed. ${ }^{33}$ Particularly for men, the high risk of accidental mortality in unemployed stands up. This finding could be explained by characteristics underlying the socioeconomic position, such as risky behaviours, lifestyles (eg, smoking or unhealthy diet), ${ }^{34} 35$ and other factors not evenly distributed in the population, like higher suicidal behaviour in unemployed. ${ }^{36}$ Our results are different from a study conducted on a sample of Italians, and based on a national health survey conducted by the Italian Statistics Institute. ${ }^{37}$ At a national level, there were inequalities in mortality by occupational status only in men, whereas no differences in mortality risks between employed and unemployed were reported in women. ${ }^{37}$

In women, we observed inequalities in mortality by occupational status, although less pronounced compared with men. Globally, CVD mortality presented higher risks, in particular for women looking for the first job and unemployed. Nearly 200000 women, who were homemakers at 


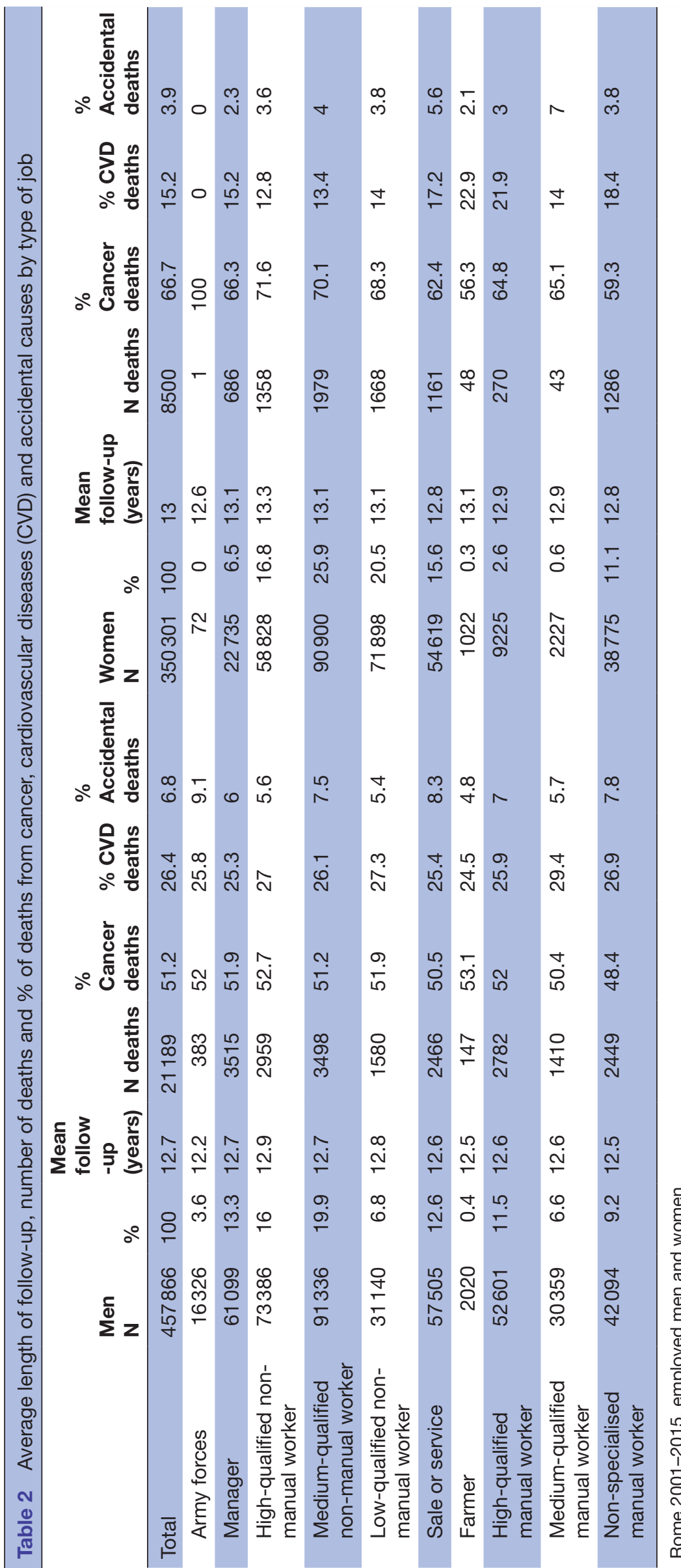

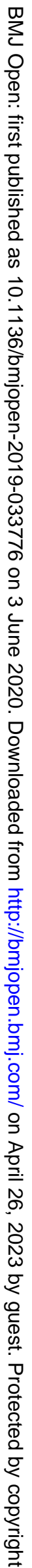



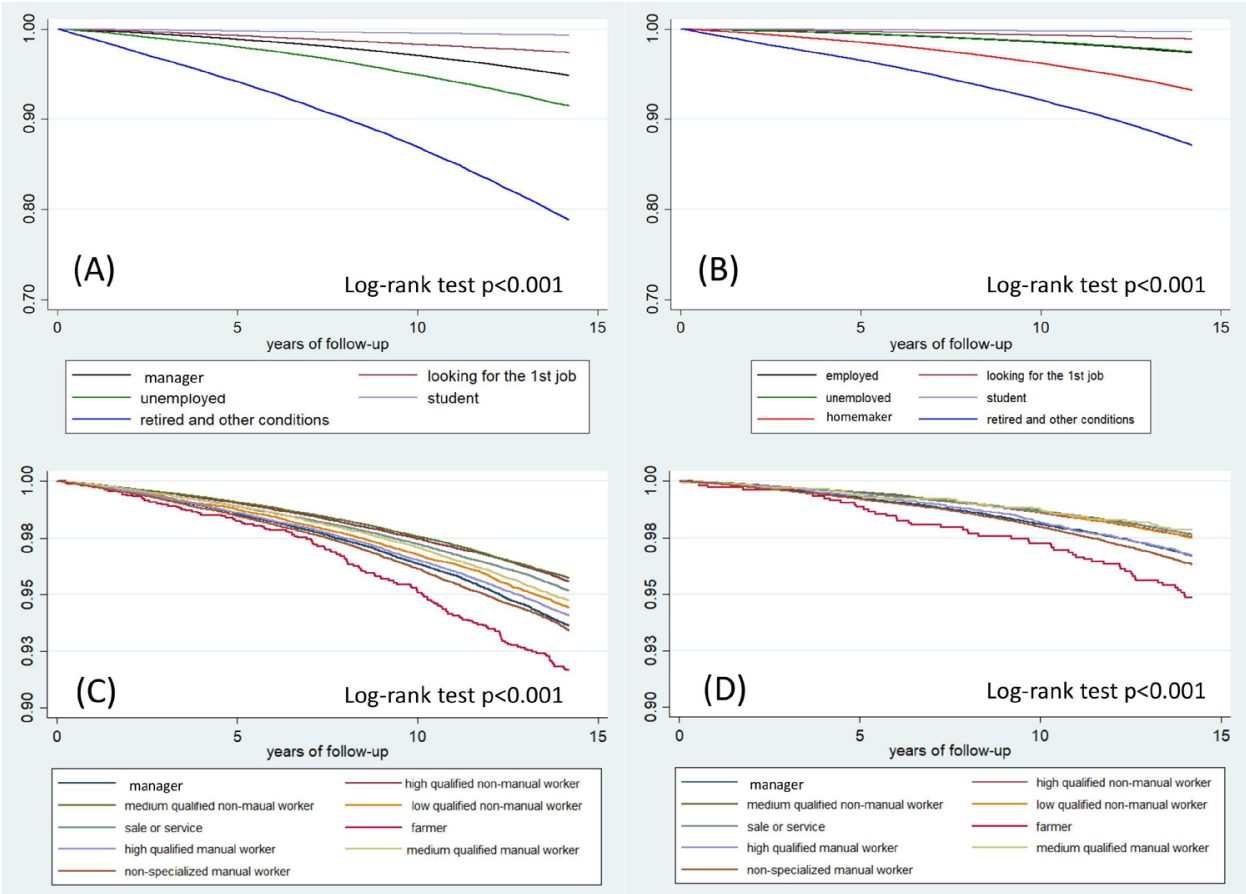

Figure 1 Kaplan-Meier curves, all-cause mortality: (A) occupational status, men; (B) occupational status, women; (C) type of job, employed men; (D) type of job, employed women.

the 2001 census, had a mortality risk higher than those employed. Homemakers had higher risk in all-cause and cause-specific mortality (in particular CVD), consistent with previous studies. ${ }^{6} 38$ These findings both, for homemakers and unemployed, could be explained by the 'status syndrome' theory: 'lack of control and low social participation have a powerful influence on disease risk'. ${ }^{40}$ Unemployed and housewives are dependent on the income of other family members, and as a consequence may have a lack of control over their lives. The social dependence can

Table 3 Association between occupational status and cause-specific mortality in men and women, Rome 2001-2015

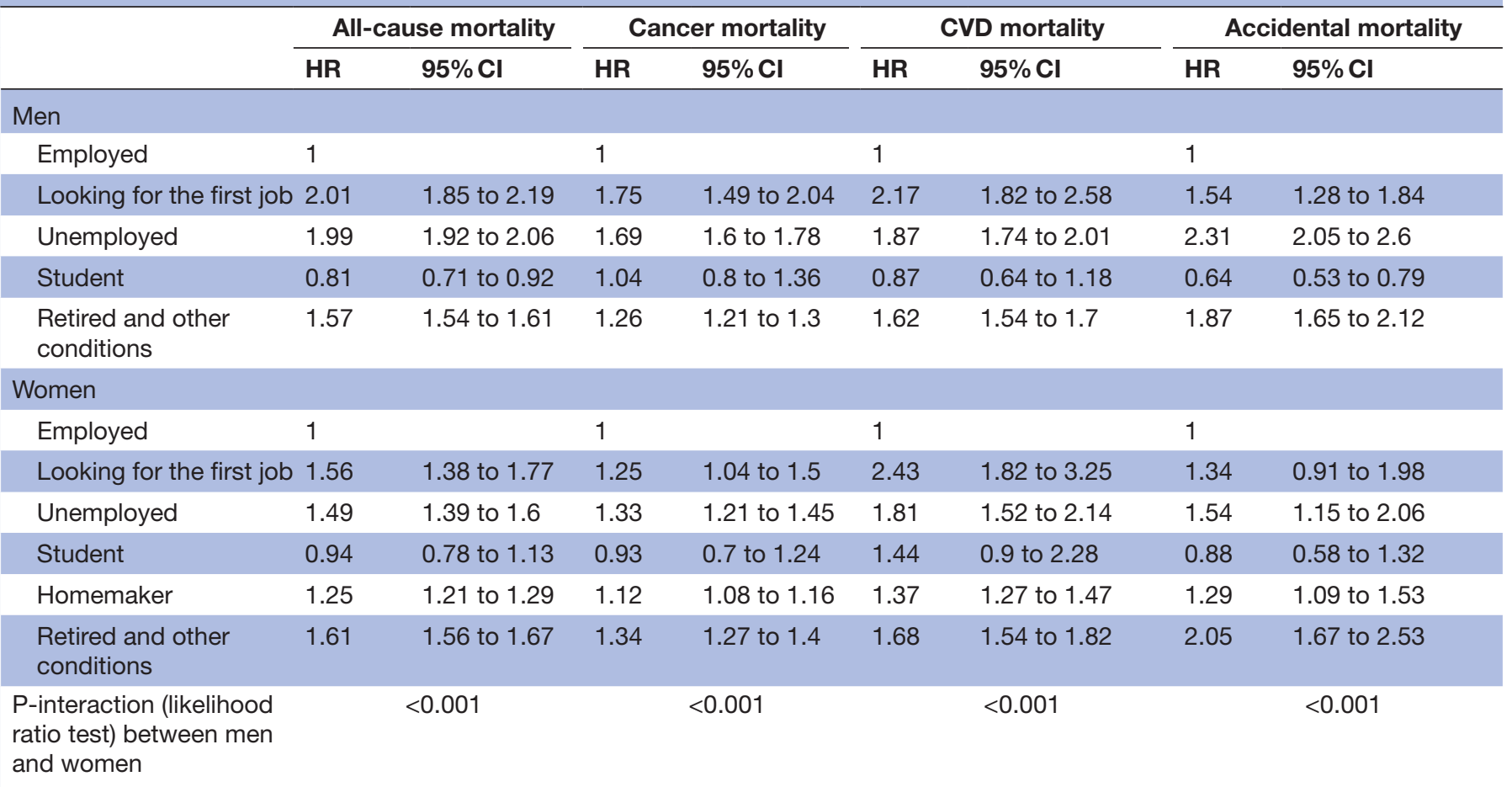

HR age-adjusted models.

CVD, cardiovascular diseases. 
Table 4 Association between type of job and cause-specific mortality in employed men and women, Rome 2001-2015

\begin{tabular}{|c|c|c|c|c|c|c|c|c|}
\hline & \multicolumn{2}{|c|}{ All-cause mortality } & \multicolumn{2}{|c|}{ Cancer mortality } & \multicolumn{2}{|c|}{ CVD mortality } & \multicolumn{2}{|c|}{ Accidental mortality } \\
\hline & HR & $95 \% \mathrm{Cl}$ & HR & $95 \% \mathrm{Cl}$ & HR & $95 \% \mathrm{Cl}$ & HR & $95 \% \mathrm{Cl}$ \\
\hline \multicolumn{9}{|l|}{ Men } \\
\hline $\begin{array}{l}\text { High-qualified non-manual } \\
\text { worker }\end{array}$ & 1 & & 1 & & 1 & & 1 & \\
\hline Low-qualified non-manual worker & 1.28 & 1.21 to 1.36 & 1.26 & 1.15 to 1.37 & 1.31 & 1.16 to 1.47 & 1.22 & 0.94 to 1.59 \\
\hline Sale or service & 1.49 & 1.41 to 1.57 & 1.48 & 1.37 to 1.59 & 1.42 & 1.28 to 1.58 & 1.58 & 1.28 to 1.94 \\
\hline Farmer & 1.53 & 1.3 to 1.8 & 1.54 & 1.24 to 1.93 & 1.39 & 1.01 to 1.92 & 1.92 & 0.81 to 3.32 \\
\hline High-qualified manual worker & 1.54 & 1.46 to 1.62 & 1.53 & 1.43 to 1.65 & 1.49 & 1.35 to 1.65 & 1.64 & 1.33 to 2.02 \\
\hline Manager & 1.07 & 0.98 to 1.17 & 1.02 & 0.91 to 1.14 & 1.17 & 0.92 to 1.49 & 0.78 & 0.44 to 1.38 \\
\hline $\begin{array}{l}\text { High-qualified non-manual } \\
\text { worker }\end{array}$ & 1 & & 1 & & 1 & & 1 & \\
\hline $\begin{array}{l}\text { Medium-qualified non-manual } \\
\text { worker }\end{array}$ & 1.16 & 1.08 to 1.24 & 1.14 & 1.05 to 1.23 & 1.25 & 1.03 to 1.51 & 1.11 & 0.78 to 1.59 \\
\hline Low-qualified non-manual worker & 1.19 & 1.11 to 1.28 & 1.13 & 1.04 to 1.23 & 1.35 & 1.11 to 1.64 & 1.12 & 0.77 to 1.62 \\
\hline Sale or service & 1.24 & 1.15 to 1.34 & 1.11 & 1.01 to 1.22 & 1.63 & 1.33 to 2 & 1.51 & 1.04 to 2.19 \\
\hline Farmer & 1.29 & 0.97 to 1.7 & 1.05 & 0.72 to 1.52 & 1.98 & 1.1 to 3.57 & 0.93 & 0.13 to 6.71 \\
\hline High-qualified manual worker & 1.28 & 1.12 to 1.45 & 1.17 & 1.01 to 1.38 & 2.03 & 1.52 to 2.73 & 1.13 & 0.55 to 2.3 \\
\hline Medium-qualified manual worker & 1.14 & 0.84 to 1.54 & 1.03 & 0.71 to 1.5 & 1.23 & 0.54 to 2.77 & 1.68 & 0.52 to 5.39 \\
\hline
\end{tabular}

HR: age adjusted models.

determine chronic stress due to the impossibility to have control over life choices, and chronic stress might activate inflammation pathways, at the basis of CVD diseases and cancer. ${ }^{40}$ In particular, homemakers also have a higher risk of exposure to domestic accidents and exposure to cleaning products. Last, but not least, the two categories comprise also persons unable to work for undeclared health reasons, which might contribute to the higher mortality risk.

From type of job analysis, similarly to national and international studies, ${ }^{10} 14-16333841$ in men a clear gradient for all-cause mortality emerged: starting from high-qualified non-manual workers, the risk increases as the specialisation of work descends. We found a significant difference between non-manual and manual workers and, within the classes, each less specialised working class presents greater risks than those more specialised, except for mediumqualified manual workers. Our results in men are similar to findings in Tuscany, ${ }^{14}$ a central Italian region: in this study, compared with upper non-manual, unskilled manual workers present a $50 \%$ increase in cancer mortality, and skilled manual workers an over $65 \%$ risk increase for external-cause mortality. The same study found differences in mortality patterns between a semirural context, like Tuscany, and an urban-industrial context, like Turin. ${ }^{14}$

In men, non-specialised manual workers had the highest risk of accidental mortality. This category, according to the census classification, includes porters and labourers of building and farming sectors, who have the highest incidence rate of fatal injuries on workplace in Rome. ${ }^{42}$ Medium-qualified manual workers had a lower risk than high-qualified manual workers. According to the census classification, the category of high-qualified manual workers includes masons and mechanics, who are exposed to professional hazards related to the work conditions. Yet, this result could be related to the higher rate of car accidents in Rome, ${ }^{43}$ that might follow a social gradient. ${ }^{44}$ Traffic and car accidents are related to the process of urban sprawl investing Rome. ${ }^{25} 2645$ Differences in CVD mortality could be due to a well-known social gradient in the distribution of chronic diseases and conditions. ${ }^{46}$

We made a special focus on female work, because other studies have investigated only some variables or 
could not find any difference by job characteristic in women. ${ }^{37} 47$ According to our findings, differences are less pronounced in women than in men. Our results showed that the real threshold for women is between not working and working. In women, the gradient across qualifications was less evident. The lower gradient in women was partially attributable to lower differences in cancer mortality. These disparities could be related to the absence of inequalities in breast cancer incidence, ${ }^{48}$ to the lower prevalence of smoking habit and alcohol consumption in women than in men, ${ }^{49}$ and to the differential sex-specific distribution of smoking habit across socioeconomic classes. ${ }^{50} 51$ The occupational differences in CVD mortality were similar across sexes. Although there were few women in highly and medium qualified manual positions, the higher mortality of high-qualified manual workers for CVD stands out particularly. It was even higher than that of non-specialised manual workers. This suggests the need for studying in-depth the causal and biological patterns related in particular to lifestyles (smoking, alcohol consumption) and work-related stress in women. ${ }^{51} 52$

This is the first study on a large administrative cohort to investigate the association between job characteristics and mortality in men and women over 14 years of follow-up using survival analysis. This study has its limitations. For all our records, the occupational status and job characteristics were available at the 2001 census, but no information on possible changes in the status or in the type of job during the 14 years of follow-up. Nevertheless, the time of follow-up was not excessively long to suggest important changes in the career track of our population. The censoring for emigration (224433 subjects) from the cohort could have introduced a bias. Emigration has not to be intended as international migration, but only as of the disenrollment from the administrative registry, that is going to live in other municipalities. In a previous study on education and mortality, the use of an inverse probability approach to take migration into account did not show differences in results from the traditional survival analysis. ${ }^{9}$ Furthermore, this cohort does not allow new entries during the follow-up. Finally, the 'healthy worker effect' has to be considered. ${ }^{53}$ The exclusion of unhealthy people from the workforce could explain the differences we found by occupational status, but also some of the differences by type of job. In fact, health status could be related to the working position attained.

Our results highlight some important problems of the productive tissue of Rome. The first concerns female occupation. In 2001, $26 \%$ of the female workforce was homemaker, and only $46 \%$ was employed. These figures offer the possibility to evaluate the capacity of labour market to provide job opportunities to women. They also suggest the necessity to improve a welfare system capable of combining work and private life choices for women. The second issue is related to the unequal distribution by sex of the senior positions, with only $6.5 \%$ of women with managerial roles versus $13.3 \%$ of men. In a city like Rome, characterised in particular by public sector employment, this represents a problematic issue. Third, the topic of the high mortality of manual working men. Evaluations on safety on workplaces go beyond the purpose of this paper. Nevertheless, improvements of health status of manual workers are needed. In general, this study provides evidence for policy-makers to develop strategies to contrast work-related factors associated to socioeconomic inequalities in mortality.

In conclusion, our results prove that in Rome there is a considerable margin for improvement to begin with the not-employed population. Health professionals and general practitioners should be aware of the need of specific categories of the population (unemployed, homemakers) to better target prevention and health promotion strategies.

Acknowledgements The authors thank Ursula Kirchmayer for her editorial advice. Contributors LP and GC conceived the study, drafted the manuscript and were responsible for the final version of the manuscript. GC handled the permissions and data collection. LP, LA and GC handled the data management and analyses. NA and MD critically revised the manuscript for important intellectual content. All authors reviewed, read and approved the final manuscript.

Funding The authors have not declared a specific grant for this research from any funding agency in the public, commercial or not-for-profit sectors.

Competing interests None declared.

Patient and public involvement Patients and/or the public were not involved in the design, or conduct, or reporting, or dissemination plans of this research.

Patient consent for publication Not required.

Ethics approval The Rome Longitudinal Study is approved by the Italian Data Protection Authority (G.U. 16-07-2019 n.165. pag.26. available at:(https://www. gazzettaufficiale.it/do/atto/serie_generale/caricaPdf?cdimg=19A0439100100010 110001\&dgu=2019-07-16\&art.dataPubblicazioneGazzetta=2019-07-16\&art. codiceRedazionale $=19$ A04391\&art.num $=1$ \&art.tiposerie $=S G$ ).

Provenance and peer review Not commissioned; externally peer reviewed.

Data availability statement Data may be obtained from a third party and are not publicly available. All data presented in the study are stored by the Department of Epidemiology-Lazio Regional Health Service. ASL Roma 1, and handled confidentially, only the research team and related Institutions have access to the data.

Open access This is an open access article distributed in accordance with the Creative Commons Attribution Non Commercial (CC BY-NC 4.0) license, which permits others to distribute, remix, adapt, build upon this work non-commercially, and license their derivative works on different terms, provided the original work is properly cited, appropriate credit is given, any changes made indicated, and the use is non-commercial. See: http://creativecommons.org/licenses/by-nc/4.0/.

ORCID iDs

Lorenzo Paglione http://orcid.org/0000-0002-9481-4376

Laura Angelici http://orcid.org/0000-0003-3731-1606

Marina Davoli http://orcid.org/0000-0003-4521-032X

Nera Agabiti http://orcid.org/0000-0003-3385-1197

Giulia Cesaroni http://orcid.org/0000-0001-7361-9072

\section{REFERENCES}

1 Weltgesundheitsorganisation. Health in 2015: from MDGs. millennium development goals to SDGs. sustainable development goals. Geneva: World Health Organization, 2015.

2 Dahlgren G, Whitehead M. Policies and strategies to promote social equity in health. Stockholm. Sweden: Institute for Futures Studies, 1991.

3 Marmot M. Social determinants of health inequalities. Lancet 2005;365:1099-104.

4 Mackenbach JP. Persistence of social inequalities in modern welfare states: explanation of a paradox. Scand J Public Health 2017;45:113-20. 
5 Marmot M, justice S. Social justice, epidemiology and health inequalities. Eur J Epidemiol 2017;32:537-46.

6 Leclerc A, Chastang J-F, Menvielle G, et al. Socioeconomic inequalities in premature mortality in France: have they widened in recent decades? Soc Sci Med 2006;62:2035-45

7 Mackenbach JP, Bos V, Andersen O, et al. Widening socioeconomic inequalities in mortality in six Western European countries. Int $J$ Epidemiol 2003;32:830-7.

8 Petrelli A, Di Napoli A, Sebastiani G, et al. Italian atlas of mortality inequalities by education level. Epidemiol Prev 2019;43:1-120.

9 Cacciani L, Bargagli AM, Cesaroni G, et al. Education and mortality in the Rome longitudinal study. PLoS One 2015;10:e0137576.

10 Mackenbach JP, Kulhánová I, Artnik B, et al. Changes in mortality inequalities over two decades: register based study of European countries. BMJ 2016;353:i1732.

11 Vineis P, Kelly-Irving M. Biography and biological capital. Eur J Epidemiol 2019;34:979-82.

12 Galobardes B, Lynch JW, Davey Smith G, Circumstances CS. Childhood socioeconomic circumstances and cause-specific mortality in adulthood: systematic review and interpretation. Epidemiol Rev 2004;26:7-21.

13 Diderichsen F, Andersen I, Manuel C, et al. Health inequality-determinants and policies. Scand J Public Health 2012;40:12-105.

14 Toch-Marquardt M, Menvielle G, Eikemo TA, et al. Occupational class inequalities in all-cause and cause-specific mortality among middleaged men in 14 European populations during the early 2000s. PLoS One 2014;9:e108072.

15 de Gelder R, Menvielle G, Costa G, et al. Long-Term trends of inequalities in mortality in 6 European countries. Int $\mathrm{J}$ Public Health 2017;62:127-41.

16 Kunst AE, Groenhof F, Mackenbach JP, et al. Occupational class and cause specific mortality in middle aged men in 11 European countries: comparison of population based studies EU Working group on socioeconomic inequalities in health. BMJ 1998;316:1636-42.

17 Hämmig O, Bauer GF. The social gradient in work and health: a cross-sectional study exploring the relationship between working conditions and health inequalities. BMC Public Health 2013;13:1170.

18 Mackenbach JP, Stirbu I, Roskam A-JR, Schaap MM, et al. Socioeconomic inequalities in health in 22 European countries. $N$ Engl J Med 2008;358:2468-81.

19 Menvielle G, Leclerc A, Chastang J-F, et al. Changes in socioeconomic inequalities in cancer mortality rates among French men between 1968 and 1996. Am J Public Health 2007;97:2082-7.

20 Artazcoz L, Cortès I, Borrell C, et al. Gender perspective in the analysis of the relationship between long workhours, health and health-related behavior. Scand J Work Environ Health 2007:33:344-50.

21 Mühlau P. Gender inequality and job quality in Europe. Mrev 2011;22:114-31.

22 European Commission. Report on equality between women and men in the European Union. Luxembourg: Publications Office of the European Union, 2018

23 Cesaroni G, Agabiti N, Forastiere F, et al. Socioeconomic differentials in premature mortality in Rome: changes from 1990 to 2001. BMC Public Health 2006;6:270.

24 Lelo K, Monni S, Tomassi F. Urban inequalities in Italy: a comparison between Rome, Milan and Naples. JESI 2018;6:939-57.

25 Iorio S, Salvatori LM, Barnocchi A, et al. Social inequalities in the metropolitan area of Rome. A multidisciplinary analysis of the urban segregation of the "formerly-Bastogi" compound. Ann lg 2019;31:211-29.

26 Lelo K, Monni S, Tomassi F. Socio-spatial inequalities and urban transformation. The case of Rome districts. Socio econ Plann Sci 2019.

27 Capolongo S, Rebecchi A, Dettori M, et al. Healthy design and urban planning strategies, actions, and policy to achieve Salutogenic cities. Int J Environ Res Public Health 2018;15. doi:10.3390/ijerph15122698. [Epub ahead of print: 29 Nov 2018]

28 Ficacci S. Roman working class searching for an identity [Tra mestiere e quartiere La classe operaia romana alla ricerca di un'identit ].Tra Luoghi e Mestieri - Spazi e Culture Del Lavoro Nell'Italia Del Novecento, 2016: 1-24.
29 Cesaroni G, Badaloni C, Romano V, et al. Socioeconomic position and health status of people who live near busy roads: the Rome longitudinal study (RoLS). Environ Health 2010;9:41.

30 Cesaroni G, Badaloni C, Gariazzo C, et al. Long-Term exposure to urban air pollution and mortality in a cohort of more than a million adults in Rome. Environ Health Perspect 2013;121:324-31.

31 World Health Organization. World health assembly. manual of the International statistical classification of diseases. injuries. and causes of death. Geneva: World Health Organization, 1977.

32 Lee H-E, Kim H-R, Chung YK, et al. Mortality rates by occupation in Korea: a nationwide, 13-year follow-up study. Occup Environ Med 2016;73:329-35

33 Duran X, Vanroelen C, Deboosere P, et al. Social security status and mortality in Belgian and Spanish male workers. Gac Sanit 2016;30:293-5

34 Vågerö D, Garcy AM. Does unemployment cause long-term mortality? selection and causation after the 1992-96 deep Swedish recession. Eur J Public Health 2016;26:778-83.

35 Voss M, Floderus B, Diderichsen F, et al. How do job characteristics, family situation, domestic work, and lifestyle factors relate to sickness absence? A study based on Sweden post. J Occup Environ Med 2004;46:1134-43.

36 Preti A, Miotto P. Suicide and unemployment in Italy, 1982-1994. J Epidemiol Community Health 1999;53:694-701.

37 d'Errico A, Piccinelli C, Sebastiani G, et al. Unemployment and mortality in a large Italian cohort. J Public Health 2019:fdz100.

38 Petrelli A, Gnavi R, Marinacci C, et al. Socioeconomic inequalities in coronary heart disease in Italy: a multilevel population-based study. Soc Sci Med 2006:63:446-56.

39 Passannante MR, Nathanson CA. Female labor force participation and female mortality in Wisconsin 1974-1978. Soc Sci Med 1985;21:655-65.

40 Marmot MG. Status syndrome: a challenge to medicine. JAMA 2006:295:1304-7.

41 Tanaka H, Nusselder WJ, Bopp M, et al. Mortality inequalities by occupational class among men in Japan, South Korea and eight European countries: a national register-based study, 1990-2015. J Epidemiol Community Health 2019;73:750-8.

42 Ragioneria Generale I Direzione Sistemi informativi di pianificazione e controllo finanziario U.O. Statistica. Accident onworkplace and professional diseases in Rome between 2010 and 2016 [Gli infortuni sul lavoro e le malattie professionali a Roma anni 2010-2015, 2016.

43 Gariazzo C, Stafoggia M, Bruzzone S, et al. Association between mobile phone traffic volume and road crash fatalities: a populationbased case-crossover study. Accid Anal Prev 2018;115:25-33.

44 Harper S, Charters TJ, Strumpf EC. Trends in socioeconomic inequalities in motor vehicle accident deaths in the United States, 1995-2010. Am J Epidemiol 2015;182:606-14.

45 Lelo K. Suburbs and fragmentation patterns: the case of Rome, 2017

46 Cockerham WC, Hamby BW, Oates GR. The social determinants of chronic disease. Am J Prev Med 2017;52:S5-12.

47 Bertuccio P, Alicandro G, Sebastiani G, et al. Mortality by occupation-based social class in Italy from 2012 to 2014. Int J Public Health 2018;63:865-74.

48 Lundqvist A, Andersson E, Ahlberg I, et al. Socioeconomic inequalities in breast cancer incidence and mortality in Europe-a systematic review and meta-analysis. Eur J Public Health 2016;26:804-13.

49 Tramacere I, Gallus S, Zuccaro P, et al. Socio-demographic variation in smoking habits: Italy, 2008. Prev Med 2009;48:213-7.

50 Faggiano F, Versino E, Lemma P. Decennial trends of social differentials in smoking habits in Italy. Cancer Causes Control 2001;12:665-71.

51 Padkapayeva K, Gilbert-Ouimet M, Bielecky A, et al. Gender/Sex differences in the relationship between psychosocial work exposures and work and life stress. Ann Work Expo Health 2018;62:416-25.

52 Rivera-Torres P, Araque-Padilla RA, Montero-Simó MJ. Job stress across gender: the importance of emotional and intellectual demands and social support in women. Int J Environ Res Public Health 2013;10:375-89.

53 McMichael AJ. Standardized mortality ratios and the "healthy worker effect": scratching beneath the surface. J Occup Med $1976 ; 18: 165-8$ 